\section{Send for Kochi}

\section{WHO is hoping that Arata Kochi, the new director of its global malaria programme, will inject new life into the scheme. As he approaches his first anniversary in the job, Christiane Rehwagen asks him how things are progressing}

In 2005 the malaria programme run by the World Health Organization reached a low point. The programme was being criticised by scientists, who accused its organisers of not following their own policies and not clearly defining treatment guidelines. Furthermore, member states were getting the impression that their money was being unwisely spent on WHO's malaria efforts.

So Lee Jong-wook, the former director general of WHO who died in May, sent for Arata Kochi, who had previously run WHO's programme to eradicate tuberculosis. He persuaded Kochi to give up his advisory post at the United Nations in New York and take up a new position as head of WHO's global malaria programme.

Now, after 10 months in his new job, Kochi says: "We are finally coming close to developing clear strategies on how to implement the three main interventions to fight malaria, and we are progressing towards making them public." The three mainstays of the programme are drug treatment, coupled with the use of bed nets treated with insecticide and indoor spraying with insecticide.

Kochi's previous record in the tuberculosis programme gives reason to hope that he will succeed where others have failed. After graduating from the Harvard School of Public Health and working for seven years as a health and nutrition expert at Unicef, the Japanese public health doctor joined WHO's tuberculosis programme in 1989.

When he joined the programme only $2 \%$ of the world's tuberculosis patients were being treated properly. Kochi initiated new strategies, such as the directly observed treatment strategy (DOTS), which increased the proportion of tuberculosis patients getting good quality treatment to more than $60 \%$. After his success with tuberculosis Dr Kochi became head of WHO's HIV and AIDS programme. Despite his success he

has kept a low profile and has given few interviews.

"I have known him when he was director of the TB programme and followed his efforts in AIDS/HIV. In both roles he was exemplary," said Amir Attaran, professor of medicine and law at Ottawa University and previously an outspoken critic of WHO's malaria efforts. He added: "In only a short time in his new job Kochi has demonstrated more courage than any of his predecessors did."
WHO's malaria programme was founded in the 1950s as one of the organisation's first major global programmes. Until the 1970 s it was considered a successful programme, eradicating malaria in the developed world and some countries in the developing world. In the past 25 years the programme has focused on bringing malaria under control in the developing world.

Although the malaria budget has been high by WHO standards, mortality from malaria has been rising since the 1970s. The high profile "roll back malaria" campaign, which WHO

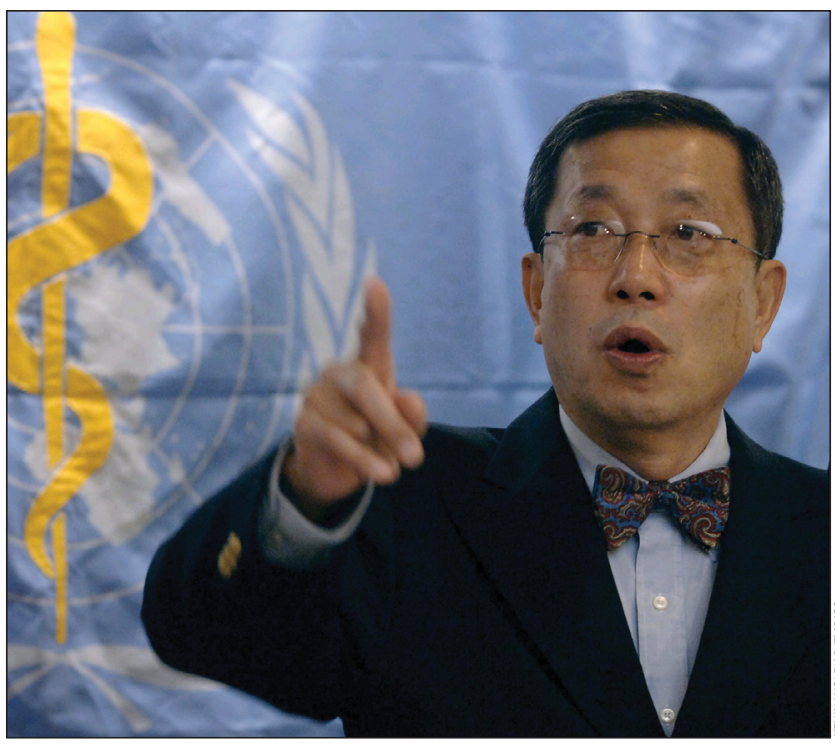

"In only a short time in his new job Kochi has demonstrated more courage than any of his predecessors did," said one commentator

launched in 1998, didn't help to achieve targets.

There are signs that Kochi is beginning to turn things around. In January this year he issued an ultimatum to the drug industry, demanding that it stop selling artemisinin as a monotherapy. By June, 17 out of 40 manufacturers of oral artemisinin monotherapies had agreed to comply with the recommendation to phase out the single drug oral treatment and to focus instead on combination therapies (bmj.com, News Extra, 20 May). "We won the war," Kochi says, "and this was only the beginning."

Indoor spraying with longlasting insecticides will be the next object of Kochi's attention. Although WHO is aware of the potential hazards of using DDT to kill mosquitoes, it believes it to be an important tool in fighting malaria. "DDT should be used where it is appropriate. Of course in malaria [compared with other infectious diseases] is the weak base of epidemiology and the difficulty of observing and measuring malaria cases and the success of interventions. We need a good modelling exercise to estimate the extent of the disease in different areas," he says.

Kochi also wishes the scientific groups working on malaria were less closed and more open to communicating with workers in other scientific areas. He explains: "For instance, it's common sense for infectious diseases that one drug can't be enough. In tuberculosis more than three drugs have been used as therapy for years. The malaria research community never thought about combining drugs until the late 1990s."

$\mathrm{He}$ adds: "The malaria community has to ask the right research questions. Time and money shouldn't be wasted on the development of drugs which help resistance to develop. And we have to find out if artemisinin combination therapies are safe in the first three months of pregnancy."

The 2005 World Health Assembly set the goal that by 2010 at least $80 \%$ of people with malaria or at risk of contracting it should be able to benefit from available interventions. If all of Arata Kochi's reforms succeed this goal may be achieved. But the struggle is far from over. $\square$ Christiane Rehwagen BMJ 